\title{
Investigation of Discoloration of Packaged Fortified Salt under Conditions Relevant to Product Packaging and Storage
}

\author{
Elisa J. T. McGee*, Levente L. Diosady \\ Department of Chemical Engineering and Applied Chemistry, University of Toronto, Toronto, Canada \\ Email: *elisa.mcgee@mail.utoronto.ca, l.diosady@utoronto.ca
}

How to cite this paper: McGee, E.J.T. and Diosady, L.L. (2016) Investigation of Discoloration of Packaged Fortified Salt under Conditions Relevant to Product Packaging and Storage. Food and Nutrition Sciences, 7, 1221-1231.

http://dx.doi.org/10.4236/fns.2016.713112

Received: September 16, 2016

Accepted: November 1, 2016

Published: November 4, 2016

Copyright $\odot 2016$ by authors and Scientific Research Publishing Inc. This work is licensed under the Creative Commons Attribution International License (CC BY 4.0).

http://creativecommons.org/licenses/by/4.0/ (c) (i) Open Access

\begin{abstract}
Double fortified salt containing both potassium iodate and ferrous fumarate microcapsules was produced at an Indian commercial facility. The packaged product became discolored, turning yellow, to a degree that would impact consumer acceptance. Therefore, there was a need for an investigation into the cause and possible remedy for this discoloration. The components of the fortified salt product, storage conditions, and processing characteristics were taken into consideration. Canadian and Indian salt samples were prepared unfortified as well as with iodine and/or iron microcapsules; stored at $25^{\circ} \mathrm{C}$ and $45^{\circ} \mathrm{C}$ in glass, polyethylene, or commercial polymer film. Some samples were heat treated prior to storage. Salt samples containing iodine that were heated before storage in packaging material turned yellow in color. From this study, it was found that due to heat and the presence of a sacrificial antioxidant component in the packaging film, potassium iodate was reduced to elemental iodine $\left(\mathrm{I}_{2}\right)$ turning packaged salt samples to a yellow/orange color. Hence it is recommended that in the manufacture of foods containing potassium iodate, the packaging material selected should be free from readily accessible antioxidants.
\end{abstract}

\section{Keywords}

Fortification, Iodate, Iodine, Iron, Polymer

\section{Introduction}

Double fortified salt (DFS) containing potassium iodate and ferrous fumarate was developed by the Food Engineering Group at the University of Toronto to combat iron and iodine deficiencies in developing countries. At present, the double fortified salt technology is at its first phase of initial commercial trials in India. Iodized salt is manu- 
factured by spraying an aqueous solution of potassium iodate onto salt. An interaction between potassium iodate and ferrous fumarate results in the reduction of iodate to elemental iodine $\left(\mathrm{I}_{2}\right)$ which subsequently sublimes, and the oxidation of iron reducing its bioavailability. Therefore, ferrous fumarate is microencapsulated before it is blended with the salt. The ferrous fumarate microcapsules are made by agglomerating ferrous fumarate powder with durum semolina and coating the agglomerates with titanium dioxide $\left(\mathrm{TiO}_{2}\right)$ for color masking. The microcapsules are further coated with soy stearine to form a physical barrier against moisture and iodine. Finally the salt is heat sealed within packages. The packaging material contains several different plastics including a polymer film of polyethylene (80\% LLDPE/20\% LDPE) and laminate material made of printed polyethylene terephthalate (PET) bound to a substrate polymer with an adhesive. Unfortunately, during these trials, it was found that samples of packaged salt turned unacceptably yellow.

Most research reports on the yellowing of food products related to post harvest yellowing of green fruits and vegetables including broccoli, Asian vegetables (i.e. Chinese mustard, choy sum, garland chrysanthemum, tatsoi, Chinese cabbage), limes, and asparagus [1]-[7]. This yellowing is due to the enzymatic degradation chlorophyll, which is not related to the yellowing of fortified salt [2]. There has been some research on the yellowing of rice where the source is thought to be a biochemical process that occurs within the rice grain that is genetically controlled; however there are also conflicting conclusions stating that it is due to presence of fungi or mold [8]. As there are no genetically controlled biochemical processes and the growth of fungi and mold is very unlikely in fortified salt, the findings from yellowing rice are not applicable.

Previous research pertaining to the yellowing of foods does not seem to apply to fortified salt; however research from the textile industry is of more relevance. Requirements of packaging polymers for textile applications are less stringent when compared to food packaging; however, similar criteria are applied when it comes to discoloration [9]. Yellowing of packaging materials in the textile industry is due to polymer degradation or reactions of additives. Antioxidant additives sacrificially prevent the oxidation (degradation) of the polymer and are chemically transformed during the process. Polymer degradation occurs when oxidation is allowed to take place, often when antioxidants are no longer present in sufficient amounts. This type of yellowing often occurs when there is low mobility of antioxidants through the material [9]. It is commonly seen in polyvinylchloride (PVC) as a prominent yellowing [9]. Phenolic antioxidants, such as butylated hydroxytoluene (BHT), are commonly used to prevent polymer degradation [9]. However, upon oxidation these antioxidants form yellow products. Contributing oxidizing agents cited from the textile industry include $\mathrm{TiO}_{2}$ pigments, catalyst residues (titanium and aluminum species that remain in the polymer), and nitrogen oxides in the air (often from gas-fired equipment) [9]. As far as yellowing of textiles themselves, this may be from microorganisms, fluorescent brightening agents, migration of dyes from cardboard packaging, as well as the influence of light and heat on the fibers, none of which apply to fortified salt [10]. However most reported issues are to 
do with storage in polyethylene or polypropylene bags [10]. Most frequently yellowing arises when nitrogen oxides react with phenolic antioxidants that are present in most polypropylene and polyethylene bags [10]. BHT is most commonly used as it is approved by the United States Food and Drug Administration (FDA). Its high mobility allows it to transfer to the textiles and cause yellowing [10].

It has been found from the literature, that many packaging plastics including PET turn yellow upon oxidation. Thus, antioxidants like BHT are added to ensure good melt processing stability of polymer films. Most antioxidants contain phenol, oxidation of these phenolic compounds results in yellow discoloration. The discoloration caused by BHT is often due to the production of stilbene quinone [11]. In double fortified salt (DFS) several factors might lead to discoloration. Potassium iodate, being an oxidizing agent, may be reduced to elemental iodine $\left(\mathrm{I}_{2}\right)$ which is yellow/violet in color. However, $\mathrm{I}_{2}$ can easily sublime from the iodized salt and be lost to the packaging material or atmosphere. The BHT present in the packaging material may react with the $\mathrm{TiO}_{2}$ from the iron microcapsules or potassium iodate leading to a yellowing of the packaging material and the salt. Free radicals found in an atmosphere due to pollution can also contribute to discoloration. Although these were the most likely causes of yellowing, potential interactions with iron and impure salt were investigated as well.

\section{Materials and Methods}

\subsection{Materials}

Indian salt, packaging film, sealed yellowed package of salt, sealed empty package, and iron microcapsules were supplied by the Micronutrient Initiative through the manufacturer GHCL Limited (Tiruporur, Tamil Nadu, India). This manufacturing company produces specialty salt under the brand name i-FLO and is producing DFS for the large scale trial. Canadian salt was obtained from Sifto Canada (Compass Minerals Canada Corp., Ontario, Canada). Potassium iodate was purchased from Sigma-Aldrich Chemicals and potassium iodate was purchased from Caledon Laboratories Limited. Sodium thiosulfate solution $(0.1 \mathrm{~N})$ was purchased from $\mathrm{BDH}$. All reagents were ACS grade. The 1.0\% starch indicator was purchased from LabChem Incorporated.

\subsection{Image Analysis}

Images were captured using a Nexus 5 or iPhone $4 \mathrm{~S}$ cellular device. The images were opened in the program Paint and sections were copied into the program ImageJ. In ImageJ the average RGB (red, green, blue) color parameters for the images were calculated. This was then converted into an HSV/HSB (hue, saturation, value/brightness) color space using an online calculator Colorizer.org [12]. HSV and HSB are two terms to represent the same color space. The results were verified using two other color conversion calculators from RapidTables.com and WorkWithColor.com [13] [14]. Colorizer was chosen because it allowed for more precise input. The HSV color space can be represented as a cone. Hue is represented using degrees from $0^{\circ}$ to $360^{\circ}$ with red, yellow, green, cyan, blue, and purple corresponding to $0^{\circ} / 360^{\circ}, 60^{\circ}, 120^{\circ}, 180^{\circ}, 240^{\circ}$, and 
$300^{\circ}$ respectively. Value measures brightness from $0 \%$ to $100 \%$ when traced from the vertex to the base of the cone. In this way, the line through the center of the cone from the vertex to the center of the base represents a value from $0 \%$ to $100 \%$ corresponding to black/gray/white. Saturation is measured from $0 \%$ to $100 \%$ traced from the aforementioned center line to the side of the cone. In the case of a color with a value of $100 \%$, the saturation is measured from the center of the base to the edge of the cone.

\subsection{Storage Stability Testing}

Samples of refined Canadian salt and commercial Indian salt were used directly or were prepared such that they contained $30 \mathrm{ppm}$ iodine added as potassium iodate, and/or iron microcapsules (at $1000 \mathrm{ppm}$ iron) and stored in different packaging materials (i.e. glass, polyethylene bags (LLDPE/LDPE), and the polymer film packaging material used in the Indian production trials). The amount of iodine and iron added were at the target values for the large scale trial. Two types of iron microcapsules were used; one type was extruder agglomerated while the other was fluidized bed agglomerated. The extrusion agglomerated microcapsules were produced in a pilot-scale processing run aimed to improve upon the fluidized bed agglomerated microcapsules that were used in the commercial trial of DFS in India. Samples were stored both in ambient conditions (approximately $25^{\circ} \mathrm{C}$ ) and at elevated temperature and humidity $\left(45^{\circ} \mathrm{C}, 60 \% \mathrm{RH}\right)$. Also, iron microcapsules in the absence of salt were stored in each of the three packaging materials under the two storage conditions. If potassium iodate was added, a $1 \%$ by weight iodine aqueous solution was used to spray the iodate onto the salt. The solution was sprayed onto the salt while the salt was mixing in a ribbon blender. If iron microcapsules were added, they were blended into the salt using the ribbon blender as well. Some samples were heated in a Blue M mechanical convection oven prior to storage. The implications of which may be relevant due heat exposure that occurs during packaging. All samples were observed on a monthly basis for color change and iodine content. There were two rounds of stability testing which are described in detail in the results section.

\subsection{Iodine Content}

Method 33.149 by the Association of Official Analytical Chemists (AOAC) was used for measuring the iodine content of the salt [15]. In this method iodate is reduced to iodine $\left(\mathrm{I}_{2}\right)$ and titrated with sodium thiosulfate using a starch indicator [15]. Four replicates were used for each sample and results are presented with error bars representing standard deviation.

\subsection{Investigation of Iodate and Packaging Material Interaction}

Packaging material was heated until its melting point in the presence and absence of potassium iodate. Also, the packaging material was heated to $130^{\circ} \mathrm{C}$, a temperature which did not cause melting, in the presence or absence of potassium iodate. This was also done with plastic from disposable water bottles, an alternative PET source. 


\section{Results and Discussion}

\subsection{Observation of Yellowed and Non-Yellowed Packages}

A sample of a sealed package containing salt and a sealed empty package were received. The salt inside the package had a slight yellowish hue but was not easily distinguishable from standard Indian salt. Empty sealed packages were clear while packages that contained salt had yellowed. This indicates that air pollution from nitrous oxide as well as processing conditions alone did not cause the yellowing. The yellow color was most concentrated along the seams of the bag but some yellowing was also seen in the main areas. Figure 1 shows the setup of the packages when photographed for comparison and areas that were compared, outlined in black. Table 1 shows the HSV parameters of the different sections of the bags. As can be seen in Table 1, the hues of the sections of the used package are closer to $60^{\circ}$ than the unused package, indicating that they are more yellow. The horizontal seam is the closest to $60^{\circ}$ with the vertical seam being next. This indicates that the heat used in fusing the package in the presence of salt increases the rate of reaction causing more intense yellowing. Heat can increase the mobility of antioxidants within the packaging material and accelerate the reaction. Salt was also observed within the seams of the package which indicates that salt is in contact with the packaging material at the time of sealing. The vertical seam may appear less yellow according to the HSV values due to the section of the seam selected for analysis, which included some of the other portion of the bag as well. The blank section of the bag was further away from $60^{\circ}$ indicating less yellowing in that section. Furthermore, the aver-

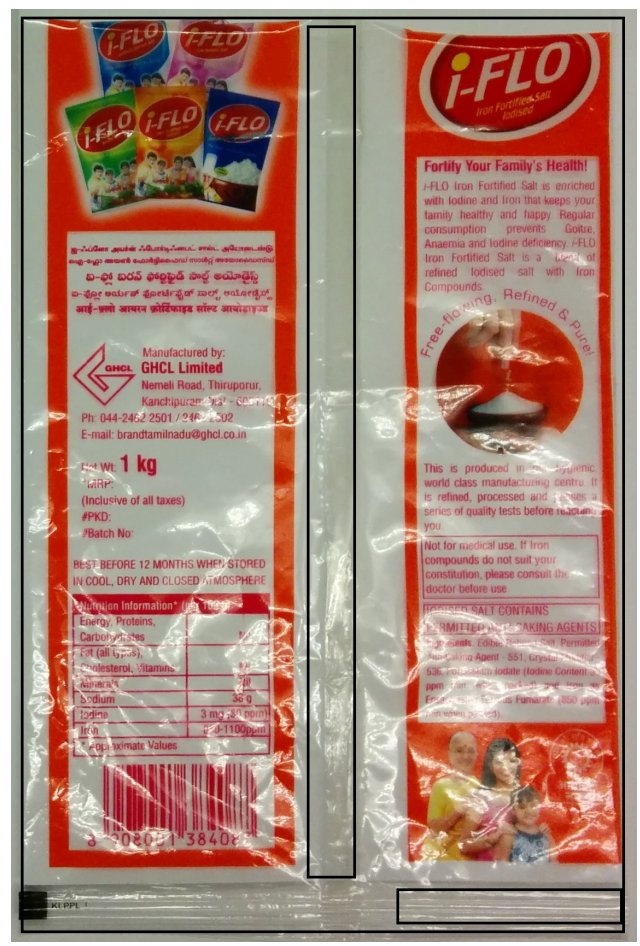

(a)

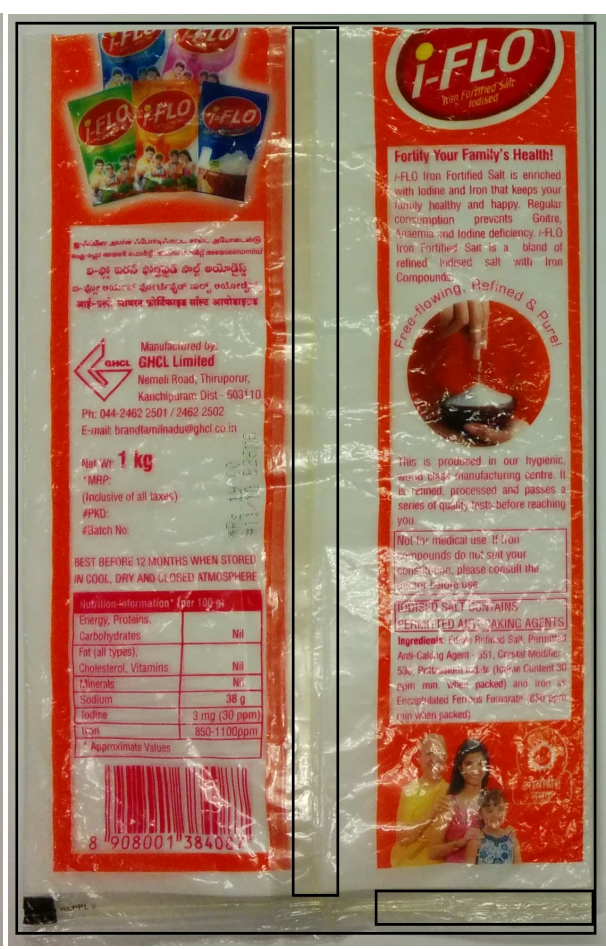

(b)

Figure 1. Sample package color comparison setup. (a) Unused salt package; (b) Used salt package. 
Table 1. Color analysis of sample packages.

\begin{tabular}{ccccc}
\hline Sample & Hue $\left(^{\circ}\right)$ & Saturation (\%) & Value (\%) & $\begin{array}{c}\text { Absolute Value of: } \\
\text { 60-Hue }\left(^{\circ}\right)\end{array}$ \\
\hline Unused Package Horizontal Seam & 33.49 & 10.38 & 63.72 & 26.51 \\
Used Package Horizontal Seam & 57.21 & 20.34 & 54.36 & 2.79 \\
Unused Package Vertical Seam & 76.97 & 9.17 & 68.90 & 16.97 \\
Used Package Vertical Seam & 68.01 & 15.85 & 68.33 & 8.01 \\
Unused Package Blank Space & 95.26 & 7.38 & 72.76 & 35.26 \\
Used Package Blank Space & 72.40 & 12.91 & 67.97 & 12.40 \\
Unused Whole Package & 15.44 & 31.21 & 67.35 & 44.56 \\
Used Whole Package & 19.58 & 39.70 & 64.59 & 40.42 \\
\hline
\end{tabular}

age hue of the entire package was the furthest away from $60^{\circ}$ because of the large amount of red coloring used in the package design. Also, it should be noted that the saturation is higher in all of the used package measurements.

\subsection{Storage Stability Testing}

The first set of samples used for stability testing included Indian salt in the presence and absence of iodine as well as in the presence and absence of extruded iron microcapsules. Also, samples containing simply extruded iron microcapsules were made. Samples were stored for one year in glass containers, polyethylene bags, or polymer film (used as the packaging material in commercial trials) at room temperature and humidity as well as elevated conditions $\left(45^{\circ} \mathrm{C}, 60 \% \mathrm{RH}\right)$. None of these samples yellowed over time. Most samples retained $>80 \%$ of their iodine over the course of a year. The exception was the Indian salt stored at $45^{\circ} \mathrm{C}$ and $60 \% \mathrm{RH}$ which represents the most rigorous testing conditions as the salt has iron impurities. The elevated temperature speeds the reaction while the elevated humidity increases iodine mobility. Also, within this sample group the iodine loss was significantly greater in samples stored in packaging film than in glass (Figure 2). This indicates that a reaction occurred between the potassium iodate and packaging material. The likely mechanism was iodate reduction to iodine $\left(\mathrm{I}_{2}\right)$ and subsequent sublimation from the salt. The presence of iron microcapsules seemed to slightly affect iodine stability but the decrease was not statistically significant. This indicates that the extruded iron microcapsules were successfully encapsulated. The soy stearine barrier inhibited the iodate-ferrous iron redox reaction which results in the creation of iodine $\left(I_{2}\right)$ as well as ferric iron. This barrier also prevents the $\mathrm{TiO}_{2}$ from reacting with antioxidants in the packaging material.

Because no color change was observed, another round of stability testing was done. In these samples the iron microcapsules were those from the commercial test of double fortified salt (fluidized bed agglomerated). Salt samples were iodized (30 ppm) and contained either $1000 \mathrm{ppm}$ or no iron as microcapsules and were made using Canadian and Indian salt. They were stored in various storage materials (glass, polyethylene bag, or polymer film) and storage conditions (ambient $\left(\sim 25^{\circ} \mathrm{C}\right)$ or $\left.45^{\circ} \mathrm{C}, 60 \% \mathrm{RH}\right)$. Also, 


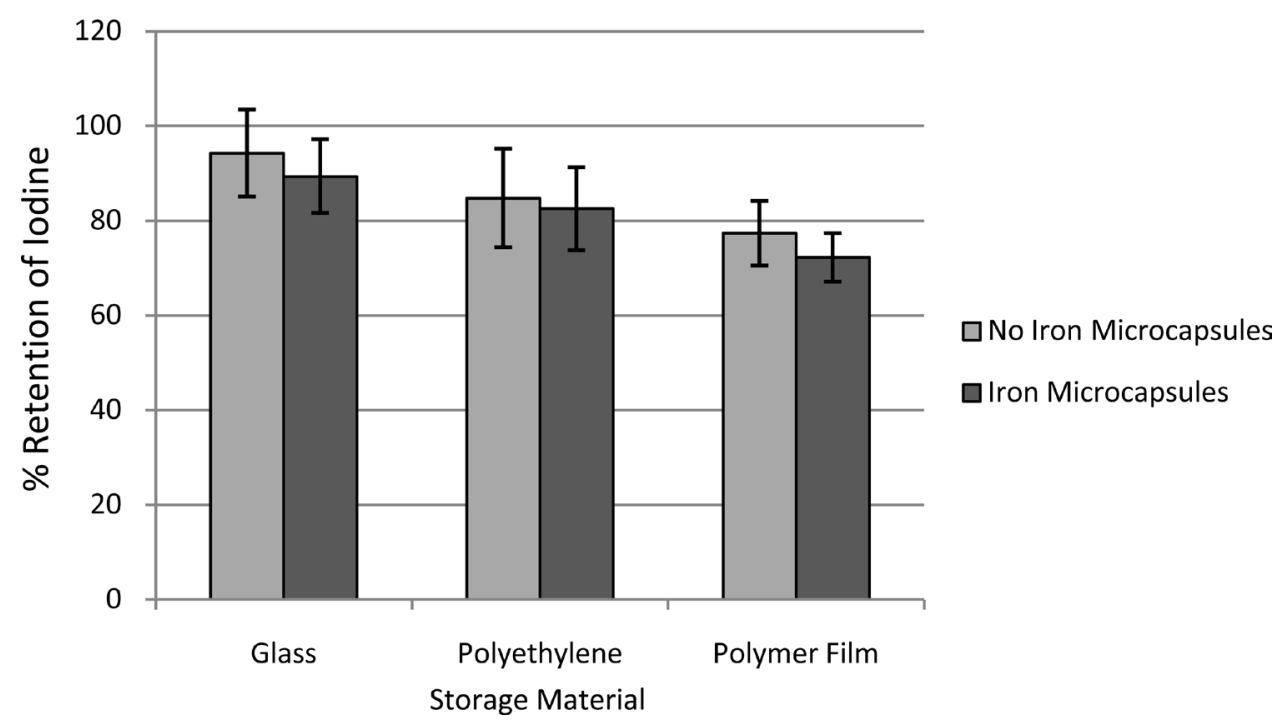

Figure 2. One year iodine retention in Indian salt stored at $45^{\circ} \mathrm{C} 60 \%$ relative humidity.

some samples packaged in the polymer film material were then heated to $130^{\circ} \mathrm{C}$ for 2 hours prior to storage. This was done to accelerate reactions as well as expose the material to heat without melting the package.

All of the iodized salt samples that were heated prior to storage at ambient conditions in the polymer film turned distinguishably yellow within 2 months. Iodized Indian salt with no iron microcapsules turned yellow after heating but before storage, therefore at both storage conditions (ambient and $45^{\circ} \mathrm{C} 60 \% \mathrm{RH}$ ) the salt turned yellow. Iodized Canadian salt with no iron microcapsules turned yellow within 1 month of storage in ambient conditions. The more rapid yellowing of Indian salt is likely due to impurities not found in the Canadian source. Both iodized Indian and Canadian salt types with added iron microcapsules took until 2 months of storage to discolor. No samples stored in glass or polyethylene bags showed yellow discoloration. Samples stored in packaging film that were not heated also did not turn yellow.

Therefore it was found that heating of the packaging material in the presence of salt causes yellowing of the salt. Also, this yellowing occurred to a greater extent in packages stored in ambient conditions over those stored at the elevated temperature. This is likely due to an increased rate of sublimation of the $I_{2}$ at higher temperatures. Yellowing occurred more slowly in salt that contained iron microcapsules. This may be due to the white coating of the microcapsules imparting some color masking to the overall salt. It also indicates that $\mathrm{TiO}_{2}$ and the iron microcapsules overall do not contribute to the yellowing of the salt.

Although some yellowing occurs in the salt, it is barely visible and would not affect the acceptance of the product. Using color analysis on the samples after 5 months of storage did not greatly distinguish the slightly yellowed salt from blank unfortified salt due to the low degree of color change (Table 2). The yellowed salt samples are all slightly closer to $60^{\circ}$ than the blanks and most have higher saturations but the differences are very small. However, the slight yellowing of the salt may be used as an indica- 
tion of a possible reaction occurring between the polymer film and the salt which causes iodate reduction to iodine.

The iodine content of the stored samples was monitored on a monthly basis. Figure 3 shows a comparison of iodine retention after 5 months of storage of the samples that became discolored (due to heat treatment prior to storage) and their non-discolored counterparts which were not heated prior to storage. Also, two samples are shown as standards that were stored in glass with no added iron. As seen in Figure 3, the discolored samples have slightly less iodine than the controls and their non-yellowed counterparts. The results are mostly statistically insignificant however they occurred with every sample which gives credit to the theory that iodate may be reacting with the packaging material, becoming $\mathrm{I}_{2}$, and then subliming from the salt.

Table 2. Color analysis of yellowed salt after 5 months of storage.

\begin{tabular}{|c|c|c|c|c|c|}
\hline Salt & $\begin{array}{l}\text { Presence of Iron } \\
\text { Microcapsules }\end{array}$ & $\begin{array}{c}\text { Storage } \\
\text { Temperature }\end{array}$ & Hue $\left({ }^{\circ}\right)$ & $\begin{array}{c}\text { Saturation } \\
(\%)\end{array}$ & Value (\%) \\
\hline Canadian Blank & No & $25^{\circ} \mathrm{C}$ & 30.86 & 6.73 & 75.61 \\
\hline Canadian & No & $25^{\circ} \mathrm{C}$ & 34.21 & 7.80 & 79.06 \\
\hline Canadian & Yes & $25^{\circ} \mathrm{C}$ & 42.86 & 4.25 & 76.29 \\
\hline Indian Blank & No & $25^{\circ} \mathrm{C}$ & 38.87 & 12.17 & 77.97 \\
\hline Indian & No & $25^{\circ} \mathrm{C}$ & 44.01 & 15.71 & 64.57 \\
\hline Indian & No & $45^{\circ} \mathrm{C}$ & 39.19 & 16.94 & 76.85 \\
\hline Indian & Yes & $25^{\circ} \mathrm{C}$ & 40.24 & 14.39 & 66.15 \\
\hline
\end{tabular}

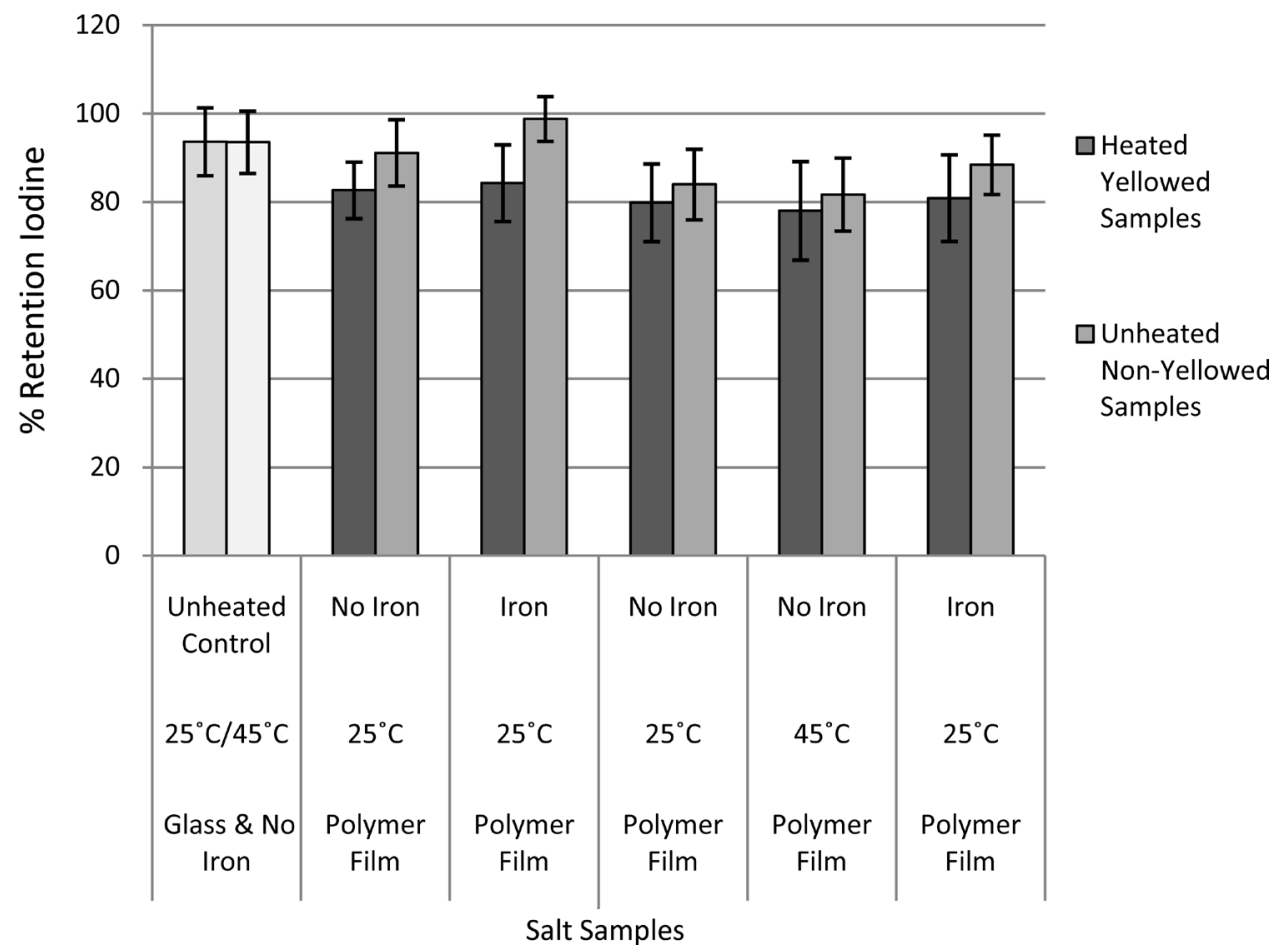

Figure 3. Five month iodine retention in discolored and non-discolored salt samples. 


\subsection{Oxidation of Packaging Material}

To further investigate the mechanism behind the discoloration, tests were done with potassium iodate in the presence of packaging film. The packaging film was melted in the presence and absence of potassium iodate to observe if oxidation occurs at a faster rate with more color development. This would explain the yellowing in the seams of the packaged salt because they are melted when sealed. The test confirmed that in the presence of potassium iodate the oxidation of the packaging material was much faster with greater color development.

Because discoloration was observed in parts of the bag that were not melted (i.e. not on the seams), an investigation of discoloration without melting was conducted. The package is subjected to heat on the packaging line since part of the package is melted to form the seams. Packaging film with and without potassium iodate was heated in an oven. The packaging material was subjected to various temperatures over time and periodically inspected for change. The temperatures and times used were as follows: $60^{\circ} \mathrm{C}$ for 20 minutes, $70^{\circ} \mathrm{C}$ for 20 minutes, $80^{\circ} \mathrm{C}$ for 20 minutes, $90^{\circ} \mathrm{C}$ for 10 minutes, $100^{\circ} \mathrm{C}$ for 15 minutes, $120^{\circ} \mathrm{C}$ for 130 minutes, and $130^{\circ} \mathrm{C}$ for 65 minutes. Table 3 shows the color analysis after the last time point of these non-rinsed samples. After this time both samples yellowed. The sample without iodine appeared slightly more orange/brown, which is indicated by the hue of 41.14 and the saturation increasing to 21.16 from 2.34. Visually the sample with iodine after the oven turned starkly bright orange/brown as indicated by the hue of 37.40 and a higher saturation of 31.67. Therefore, yellowing may occur in heated packaging that is not melted and may become orange especially in the presence of potassium iodate. To note, the glossiness of the package was compromised and thus some softening had occurred.

It was possible that the discoloration was due to the oxidation of the packaging material and/or the reduction of potassium iodate to iodine. So, strands of packaging material were heated $\left(130^{\circ} \mathrm{C}\right.$ for 2 hours) and rinsed with water and set atop a white background to compare color (Table 3, rinsed samples). All heated packaging material was slightly more saturated yellow/orange than the unheated packaging material. Also, saturation of color increased slightly if potassium iodate was present. However the difference in saturation between the heated polymer film without iodine and with iodine was much smaller if they had been washed. Heated polymer film with potassium iodate also appeared much more yellow/orange before rinsing compared to after rinsing. Thus potassium iodate must have been converted into iodine $\left(\mathrm{I}_{2}\right)$ and subsequently removed by rinsing. Therefore, yellowing was caused both by the reduction of iodate to iodine and the oxidation of the packaging material.

Discoloration of the samples was expected to be caused by PET oxidation or oxidation of antioxidants found in the polyethylene causing packaging material discoloration and the conversion of potassium iodate to yellow iodine. To investigate this, plastic from disposable water bottles (also made of PET) were cut and heated in the presence of $\mathrm{KIO}_{3}$ and in the absence of it. Also, $\mathrm{KIO}_{3}$ was heated on its own. They were heated to $130^{\circ} \mathrm{C}$ for 2 hours. None of the samples yellowed. Therefore, PET itself was not the 
Table 3. Color analysis of unmelted polymer film.

\begin{tabular}{ccccc}
\hline Pretreatment & Presence of Iodate & Hue $\left(^{\circ}\right)$ & Saturation (\%) & Value (\%) \\
\hline Unheated & \multicolumn{3}{c}{ Non-Rinsed Samples ${ }^{\mathrm{a}}$} \\
Unheated & No & 260.81 & 2.34 & 48.96 \\
Heated & Yes & 345.09 & 1.90 & 53.04 \\
Heated & No & 41.14 & 21.16 & 57.92 \\
& Yes & 37.40 & 31.67 & 50.64 \\
Unheated & & & & \\
Heated & Rinsed Samples ${ }^{\mathrm{a}}$ & & 61.17 \\
Heated & No & 29.44 & 9.59 & 61.44 \\
& No & 30.66 & 11.36 & 62.08 \\
\hline
\end{tabular}

a. Data sets for non-rinsed samples and rinsed samples were obtained using different lighting conditions.

cause of the discoloration. A reducing agent (likely an antioxidant) must be present in the packaging material causing the reduction of potassium iodate to iodine and yellowing the packaging material.

\section{Conclusion}

Discoloration of double fortified salt, observed in commercial samples produced and distributed in India, was not due to the added iron premix. The discoloration was most likely due to an interaction between potassium iodate (an oxidizing agent) and antioxidants in the packaging material. Yellowing of the salt is caused when packages containing salt are heated and then stored at room temperature. The packages are exposed to high temperatures when they are sealed on the manufacturing line. Local melting in the presence of potassium iodate causes the rapid oxidation of the packaging material and color development. This explains the prominent yellowing of the seams of the sealed package. Furthermore, yellowing of the packaging material likely occurred due to the oxidation of antioxidants added to the packaging polymer. Yellowing in the presence of potassium iodate and heat does not occur due to the presence of PET alone. Therefore, it is recommended that for the manufacture of foods containing iodate the packaging material should not contain any readily accessible antioxidants as preservatives or plasticizers.

\section{Acknowledgements}

This work was carried out with the aid of a grant from the Micronutrient Initiative, Ottawa, Canada through the financial assistance of the Government of Canada through the Department of Foreign Affairs, Trade and Development (10-0988-FOODBI-20). Publication was aided by the International Development Research Center, Ottawa. It was also financially aided by the Colin Hahnemann Bayley Fellowship in Chemical Engineering at the University of Toronto. 


\section{References}

[1] Chen, L.O., Hwang, J., Charng, Y., Sun, C. and Yang, S. (2001) Transformation of Broccoli (Brassica oleracea var. Italica) with Isopentenyltransferase Gene via Agrobacterium Tumefaciens for Post-Harvest Yellowing Retardation. Molecular Breeding, 7, 243-257.

http://dx.doi.org/10.1023/A:1011357320259

[2] Adams, J.B. and Brown, H.M. (2007) Discoloration in Raw and Processed Fruits and Vegetables. Critical Reviews in Food Science and Nutrition, 47, 319-333. http://dx.doi.org/10.1080/10408390600762647

[3] Able, A.J., Wong, L.S., Prasad, A. and O’Hare, T.J. (2003) The Effects of 1-Methylcyclopropene on the Shelf Life of Minimally Processed Leafy Asian Vegetables. Postharvest Biology and Technology, 27, 157-161. http://dx.doi.org/10.1016/S0925-5214(02)00093-5

[4] Mampholo, B.M., Sivakumar, D., Beukes, M. and van Rensburg, W.J. (2013) Effect of Modified Atmosphere Packaging on the Quality and Bioactive Compounds of Chinese Cabbage (Brasicca rapa L. ssp. Chinensis). Journal of the Science of Food and Agriculture, 93, 20082015. http://dx.doi.org/10.1002/jsfa.6007

[5] Caron, V.C., Jacomino, A.P., Sarantópoulos, C.I.G.L. and Miguel, A.C.A. (2015) Carnauba Wax and Modified Atmosphere in Refrigerated Preservation of 'Tahiti' Acid Limes. Packaging Technology and Science, 28, 647-656. http://dx.doi.org/10.1002/pts.2133

[6] Esturk, O., Ayhan, Z. and Gokkurt, T. (2014) Production and Application of Active Packaging Film with Ethylene Adsorber to Increase the Shelf Life of Broccoli (Brassica oleracea L. var. Italica). Packaging Technology and Science, 27, 179-191.

http://dx.doi.org/10.1002/pts.2023

[7] Chinsirikul, W., Klintham, P., Kerddonfag, N., Winotapun, C., Hararak, B., Kumsang, P. and Chonhenchob, V. (2014) Porous Ultrahigh Gas-Permeable Polypropylene Film and Application in Controlling In-Pack Atmosphere for Asparagus. Packaging Technology and Science, 27, 313-325. http://dx.doi.org/10.1002/pts.2027

[8] Bryant, R.J., Yeater, K.M. and Belefant-Miller, H. (2013) The Effect of Induced Yellowing on the Physicochemical Properties of Specialty Rice. Journal of the Science of Food and Agriculture, 93, 271-275. http://dx.doi.org/10.1002/jsfa.5751

[9] Henman, T.J. (1987) The Role of Packaging Additives in Yellowing. Textile Progress, 15, 25-36. http://dx.doi.org/10.1080/00405168708688906

[10] Bangee, O.D., Wilson, V.H., East, G.C. and Holme, I. (1995) Antioxidant-Induced Yellowing of Textiles. Polymer Degradation and Stability, 50, 313-317. http://dx.doi.org/10.1016/0141-3910(95)00156-5

[11] Allen, N. and Edge, M. (1992) Fundamentals of Polymer Degradation and Stabilization. Elsevier Science Publishers Ltd., Barking, 27-28.

[12] Colorizer (2016). http://colorizer.org/

[13] RapidTables.com. (2016) RGB to HSV Color Conversion. http://www.rapidtables.com/convert/color/rgb-to-hsv.htm

[14] WorkWithColor.com. (2013) Color Converter. http://www.workwithcolor.com/color-converter-01.htm

[15] Williams, S. (1984) Method 33.149. In: Williams, S., Ed., Official Methods of Analysis, 14th Edition, The Association of Official Analytical Chemists, Inc., Arlington, 638. 
Submit or recommend next manuscript to SCIRP and we will provide best service for you:

Accepting pre-submission inquiries through Email, Facebook, LinkedIn, Twitter, etc.

A wide selection of journals (inclusive of 9 subjects, more than 200 journals)

Providing 24-hour high-quality service

User-friendly online submission system

Fair and swift peer-review system

Efficient typesetting and proofreading procedure

Display of the result of downloads and visits, as well as the number of cited articles

Maximum dissemination of your research work

Submit your manuscript at: http://papersubmission.scirp.org/

Or contact fns@scirp.org 